\title{
Towards improved public awareness for climate related disaster risk reduction in South Africa: A Participatory Development Communication perspective
}

\author{
Tigere Chagutah \\ $\mathrm{PhD}$ candidate in Communication Studies, \\ North-West University, Potchefstroom Campus, South Africa \\ email: 21845468@nwu.ac.za
}

\section{ABSTRACT}

Southern Africa has frequently been struck by damaging climate hazards which increasingly continue to threaten sustainable development efforts. Ominously, climate models predict that the incidence of major 'wet' events, such as floods and cyclones will increase in frequency against the background of a changing climate. Unfortunately, local mechanisms for communicating and raising public awareness of the consequent risks and appropriate risk reduction options remain weak. At the core of policy responses to the threat posed by climate related hazards, the South African government has adopted a disaster risk reduction approach to disaster management. This article details how, among many other measures to limit the adverse impacts of natural hazards, South Africa’s National Disaster Management Framework calls for the implementation of effective public awareness activities to increase the knowledge among communities of the risks they face and what risk-minimising actions they can take. Emphasis is laid on the importance of information provision and knowledge building among at-risk communities. Citing established theories and strategies, the author proposes a participatory development communication approach through Development Support Communication strategies for the provision of disaster risk reduction public awareness activities by government and other disaster risk reduction role-players in South Africa. By way of a review of completed studies and literature, the article provides guidance on the planning and execution of successful public communication campaigns and also discusses the constraints of communication campaigns as an intervention for comprehensive disaster risk reduction.

\section{KEYWORDS}

disaster risk reduction, Development Communication, Development Support Communication, public awareness, public communication campaigns, national disaster management framework, climate disasters 


\section{Introduction}

Southern Africa has, in the recent past, been hit by a barrage of sudden onset climate- related natural disasters (Hirji et al., 2002). South Africa has not been spared, with unprecedented flooding being experienced in many areas across the country. In 2008 alone, by August, more than 4000 dwellings and 18000 people had been affected by flooding in the Western Cape, while the impacts in KwaZulu-Natal prompted the declaration of a state of disaster (Msengana-Ndlela, 2008). Sudden onset natural disasters, such as devastating floods, violent hailstorms, heavy snowfalls and gale-force winds are a regular occurrence in South Africa (South Africa, 2007:15).

A total of 946 hazardous events were recorded in South Africa between the years 1800 to 1995 . Of the hazardous events recorded, 'wet' events (floods, hailstorms, cloudbursts, snow, heavy rain, torrential rain) occurred in approximately 59 percent of cases, while 'windy' events (tornados, storms, thunderstorms, gales, whirlwinds, hurricanes, sandstorms, waterspouts) occurred in 33 percent of cases (South Africa, 2007:16-17).

Although there have been huge technological advances that now allow for the extremely accurate monitoring, prediction and forecasting of extreme weather conditions in South Africa, local mechanisms for communicating and for raising the public awareness of risk and risk reduction options are in most cases very weak (Buys, 2005:8). Even where such systems exist, very often communities do not respond appropriately to early warnings, either because the message is poorly constructed or because of a lack of choice (Buys, 2005:8).

Globally, major incidences of climate related sudden onset hazards have had adverse effects on communities, development efforts, and national economies through their detrimental impacts on critical human, natural, infrastructural and other material resources (UNISDR, 2004:2-3). Communities have been drawn into cycles of vulnerability and loss, as successive disasters have struck before they could fully recover from previous catastrophes (Wisner et al., 2004).

Furthermore, climate models predict an increase in the frequency and intensity of climate related natural disasters in the southern African region against the backdrop of a changing climate (Engelbrecht, in Shulze, 2005; Engelbrecht et al., 2008). The Southern African Environment Outlook (SADC, 2008) reports that regional average temperatures have risen by more than 0.5 degrees Celsius over the past century. Continued warming will lead to irregular rainfall, frequent flooding and increased cyclonic activity, amongst other impacts.

In South Africa, the Department of Environment and Tourism states that predictions over the next 50 years are that climate change will cause less rainfall, especially in the western parts of South Africa, and higher temperatures, particularly in the interior, with an increased frequency of floods and droughts (DEAT, 2006a:5).

At the core of policy responses to the threat of climate related, and other, disasters in South Africa is minimising the vulnerability and disaster risks in communities, in order to avoid or to limit the adverse impacts of these hazards, and facilitate sustainable development, i.e. 
Disaster Risk Reduction (DRR). Effective disaster management, with a strong emphasis on risk reduction, is an imperative for South Africa (DEAT, 2006b:289).

However, this policy thrust is fairly recent in South Africa. Until June 1994, South Africa did not have a holistic approach to deal with disasters and issues of risk; instead it viewed disasters as rare 'acts of God' that could be neither predicted nor avoided. This approach resulted in a disaster management thrust that was solely reactive and focused only on post-disaster measures designed to deal with the consequences of a disaster (Van Niekerk, 2006:96).

More recently however, legislative, programmatic and academic enquiry efforts have resulted in the development of a comprehensive disaster risk reduction programme with an oriented framework for disaster management. Among others, some of these efforts include the promulgation of the Disaster Management Act 57 of 2002 and the institutions and procedures it established at the various levels of government, including the South African National Platform for DRR and scholarly research towards the development of A Comprehensive Framework for Multi-Sphere Disaster Risk Reduction in South Africa (Van Niekerk, 2005).

The South African National Disaster Management Framework 2005 (NDMF), which arises out of the Disaster Management Act 57 of 2002, is divided into four key performance areas (KPAs) and three 'enablers' - aspects that need to be present in all four of the key performance areas in order for them to be implemented successfully (South Africa, 2005:2).

The key performance areas and enablers are:

-KPA1: Integrated institutional capacity for disaster risk management

-KPA2: Disaster risk assessment

-KPA3: Disaster risk reduction

-KPA4: Response and recovery

- Enabler 1: Information management and communication

- Enabler 2: Education, training, public awareness and research

- Enabler 3: Funding arrangement for disaster risk management

Various national, regional and global frameworks for disaster risk management now exist, among them the NDMF and Van Niekerk's Comprehensive Framework for Multi-Sphere Disaster Risk Reduction in South Africa (2005); The Africa Regional Strategy for Disaster Risk Reduction; and The Hyogo Framework for Action - a global blueprint for disaster risk reduction efforts during the decade 2005-2015 - have identified many fundamental elements in a disaster reduction strategy.

These elements include an increased political will and commitment, along with governance and legislation in support of DRR; improved risk assessment; education and increased public awareness of DRR; reduction of the underlying risks; provision of finances and resources for DRR and the integration of DRR into emergency response management. However, the priorities, relative emphasis and specific ways of implementation must take into account those practices that are most suited to local conditions, understanding and effectiveness (UNISDR, 2004:14). 
As a developing State, the South African Government is typically financially burdened and hamstrung in delivering adequate risk minimising physical infrastructural interventions. Also, low income communities cannot afford insurance and other financial risk transfer tools. Therefore, the emphasis must fall on the public awareness of appropriate pro-active and pre-emptive (risk minimising) actions. These measures may prove to be the most immediately achievable means of intervention.

Disasters can be substantially reduced if people are well informed about measures they can take to reduce vulnerability - and if they are motivated to act (UNISDR, 2005:9). Twigg (2004:176) emphasises that all disaster reduction programmes should include communications and awareness-raising as a central, ongoing element, and should have a clear strategy for doing this. Information is crucial; it may be the only form of disaster preparedness that the poorest people can afford (IFRC, 2005:12).

\section{Public awareness for disaster risk reduction in South Africa}

A review of public awareness activities for the years 2006 and 2007 within the nine provinces of South Africa shows that seven provincial disaster management centres (Eastern Cape, Free State, Gauteng, KwaZulu-Natal, Limpopo, Mpumalanga, and the Western Cape) undertook some form of public awareness activities, while in the Northern Cape "programmes were suspended due to cost containment measures" (South Africa, 2007:126). No public awareness activities are reported to have taken place in the North-West province.

The importance of a clearly formulated and successfully implemented public awareness strategy within the broader disaster risk reduction framework in South Africa cannot be overstated. Within the context of DRR, public awareness activities entail the development of a public awareness policy, programmes and materials, and media involvement in communicating risk and awareness-raising, with the goal of changing behaviours so that communities can be more resilient to such natural disasters (UNISDR, 2004).

In South Africa, The NDMF addresses requirements to promote and support a broad-based culture of risk avoidance through strengthened public awareness and responsibility. Enabler 2 within the Framework calls for the promotion of "a culture of risk avoidance among stakeholders by capacitating all role players through integrated education, training and public awareness supported by scientific research."The NDMF (South Africa, 2005:83) cites the implementation of public information campaigns and other communication avenues through the media, as being critical success factors in order to inculcate risk-avoidance behaviour by all stakeholders and to operationalise Enabler 2 of the Framework.

However, as Buys (2005:8) notes, local mechanisms for raising the public awareness of climate related risks and risk reduction options remain weak, with no observable change of behaviour, even where attempts are made to build a culture of risk avoidance through communication interventions. To bridge this gap between the provision of information and appropriate societal response to environmental change development scholars and practitioners have often turned to development communication. Development communication campaigns have been used 
extensively since the 1960s (Snyder, 2003:168). Moemeka (2000:13) defines Development Communication as the application of the principles and practices of the exchange of ideas towards the achievement of development objectives.

\section{Development communication: A brief history}

One of the most powerful discourses to emerge after World War II, with enormous social, cultural, and economic consequences, was the discourse on development predicated on the modernist hallmarks of reasoning and rationality (Melkote, 2003:130). Under the dominant paradigm (also known as 'modernisation') it was assumed that the causes of underdevelopment were inherent in the societies of the Third World, and the obvious way for the less-developed countries to develop was for them to 'catch up' and become like the developed countries.

The route of modernisation was to transform the people and to implant new values and beliefs. The transfer of values, information and knowledge was to be achieved through 'communication' (Melkote, 2003:135).

The role of communication was to transmit pro-development innovations and skills to an unsuspecting and passive audience, mostly through the use of the mass media, but also through extension workers, particularly agricultural and health field-workers. It was essentially a propersuasion exercise to win over followers to the new concept of development as enunciated by donor agencies, national governments, scientists and other 'experts' (Melkote \& Kandath, 2001:190). The mass media, especially radio, were roped in to spread the message of extension even further than change agents could manage and to act as a 'magic multiplier' of the proinnovation and top-down messages.

The dominant paradigm of development underwent extensive interrogation and criticism of its top-down and paternalistic development and development communication models by scholars and practitioners in the 1970s (Huesca, 2003:209). Alternative pathways to development were put forward. An important element of these new conceptions of development was the participation of the affected people in development planning and implementation (Snyder, 2003:172). Such participatory approaches stress the importance of the cultural identity of local communities and of democratisation and full participation at all levels of planning, development and the implementation of development initiatives and development communications.

\section{Participatory Development Communication}

Development workers now accept that they have to listen to the people, and that problems and solutions must be collectively identified (Twigg, 2004:166). Participation is held as being necessary in order to share information, knowledge, trust, commitment, and a right attitude in development planning and implementation. Communities should not be passive recipients of information; and development efforts must be based on faith in the people's capacity to contribute and participate actively in the task of transforming society (Servaes, 2004:61).

Often, information and educational activities are added onto projects rather than being integral parts of them, the methods chosen for communicating are inappropriate, and the com- 
munities at risk have no opportunity to present their views (Twigg, 2004:165). In South Africa, the Disaster Management Act 57 of 2002, places the responsibility to plan for and implement disaster risk reduction activities on the provincial or local spheres of government (Van Niekerk, 2006:101).

Thus it is in these spheres of government that expertise for the development and implementation of fully participatory public awareness activities should be strengthened. However, few disaster managers possess this kind of expertise (Twigg, 2004:165). Most disaster managers work from the assumption that people neither fully understand the risks they face, nor do they know how to deal with them (Wisner et al., 2004).

This approach sees risk education purely as a top-down communications exercise where messages are transmitted from small groups of experts to the uninformed masses. However, this is insufficient by itself because the communication process is not informed by communities' experiences and perceptions of risk, or by the impact of their socio-economic circumstances on the way they see and manage risks (Twigg, 2004:166).

With new emphases being placed on the participation of the beneficiaries in the social change process, a reorientation of the role of communication in development has been realised. The term 'development communication', which signified top-down, authority- driven and prescriptive models has been replaced by the idea of communication as a development-supported tool (Ashcroft \& Masilela, 1989 and Jayaweera, 1987 in Melkote \& Kandath, 2001:191).

Thus, Development Support Communication (DSC) was conceived to represent a participatory, people-to-people and more democratic model of communication in development.

\section{DSC: A vehicle for improved disaster risk reduction public awareness}

This article calls for the deployment of the participatory methods and strategies of Development Support Communication to ensure effective risk and risk reduction knowledge among at-risk communities. Recent advances in development support communication have spawned models that stress contextual factors and emphasise goals such as self-reliance, meeting basic needs and cultural autonomy (Melkote \& Kandath, 2001:191). The role of communication has evolved to encompass more democratic channels and co-equal knowledge sharing between the benefactors and the beneficiaries of development initiatives.

The DSC approach does away with the development communication emphasis on the use of mass media in development communication information campaigns. Instead it emphasises the use of the 'little' media (traditional media, group and interpersonal communication) which give the developing community an opportunity to co-create meaning with the assistance of a facilitator (Burger, 1999:91).

Development Support Communication makes use of all available structures and means of information sharing. In addition to mass media, DSC uses participatory community media and traditional folk media, such as theatre, song and dance. It also makes use of both formal groups 
and non-formal channels of communication, such as women's and youth associations, as well as places where people gather, such as markets, churches, festivals, and meetings (FAO, 2002:11).

In South Africa, there is an increasing thrust to integrate and mainstream Disaster Risk Management as an integral part of development planning at the local level through the Integrated Development Planning (IDP) process. Disaster management as an activity must be incorporated into each and every phase of the IDP (South Africa, 2000, South Africa, 2002 and PIMMS, 2003 in Van Niekerk, 2006). As such, the strategies of development support communication are of paramount importance to ensure the inclusion of all stakeholders in the planning and implementation of DRR activities as an integral part of the development process at all levels of government.

Steinberg (1996:579) emphasised the inclusion of development support communication in any large-scale urban development programme from the project formulation stage, and the integration of development support communication components in any (integrated) urban development programme throughout all its stages. The present practice of urban management in most developing countries shows largely an exclusion and ignorance of development support communication (Steinberg, 1996:567).

Through public awareness activities DRR role-players aim to "motivate people to become involved in activities that can reduce the risks to which they are exposed," (UNISDR, 2004:284). In doing so, DRR role-players make use of established development support communication strategies. The most common of these are discussed below.

\section{Theories and strategies in communication for development}

From within the modernisation paradigm, traditional public information and communication campaigns have been designed along the perspective of Everett Rogers' "diffusion of innovations" theory. This theory suggests that by transmitting information (e.g., via mass media) from a sender to a receiver through a linear, unidirectional process, modern values can be instilled and ideas changed, resulting in changed behaviour in individuals (Waisbord, s.a.).

Proponents for innovation and diffusion ideas in the design of development communication and information campaigns usually adopt a "two-step flow" approach by combining mass media and interpersonal communication channels (Servaes, 2004; Waisbord, 2005). This approach suggests that the media do not operate in a social vacuum and that the dissemination of ideas from the media to individuals is mediated through other persons - opinion leaders.

Waisbord (2005:81) argues that mass media-stimulated interpersonal communication can be effective in a behavioural change intended communication campaign. More recently, a multistep flow model is now more generally accepted. This model is similar to the two-step flow model, but admits to more possibilities for the path through which new ideas are passed via a social network of individuals (Littlejohn, 1996:335). 
Melkote (in Mody, 2003:135) states that, "over time, diffusion theory alone proved inadequate as a guide to communications planning in development campaigns". Among some of the inadequacies of the diffusion model identified by Melkote are the absence of feedback from message recipients and the imprecise understanding of the diffusion concept.

Other prominent strategies in the modernisation tradition include social marketing which uses marketing techniques to promote socially beneficial practices or products by providing information to help fulfil uncovered demand. Snyder (2003:171) cites Andreasen's (1995) definition of social marketing as, "the application of commercial marketing technologies to the analysis, planning, execution, and evaluation of programs designed to influence the voluntary behaviour of target audiences in order to improve their personal welfare and that of their society."

Burton (1998:89) discredits this approach for its emphasis on induced (top-down) behavioural change that is to be tracked directly back to a media stimulus. However, Snyder (2003:171172) situates the strength of social marketing in incorporating audience needs in deciding what an intervention should promote and how it should be promoted. This is achievable if the necessary formative research, that is part of this strategy, is carried out prior to the implementation of the communication campaign.

Another strategy, Education-entertainment, uses media such as radio, television, video and folk theatre to carry out behavioural change at individual and community levels by disseminating educational information embedded in entertainment programmes. Shaped by Albert Bandura's social learning theory, the strategy is premised on the idea that individuals learn behaviour by observing role models. Using this strategy, the Armenian National Survey for Seismic Protection working with the Armenian Ministry of Science and Education has developed and staged a theatrical performance "Terra non-Firma", in which children learn the basics of seismic behaviour and protection techniques through interactive education-play (Asian Disaster Risk Reduction Centre, 2008).

Entertainment-education programmes facilitate social change at the individual level by influencing awareness, attention and behaviour, and at the community level by serving as an agenda setter or by influencing public and policy initiatives in a socially desirable direction (Singhal and Rogers, 1999, in Melkote \& Steeves, 2001:140).

\section{Success factors for disaster risk reduction communications}

Modern mass media and alternate or parallel networks of folk media or interpersonal communication channels are not mutually exclusive. Mass and community media, small/alternative media, cultural/traditional media and other community communication contexts are best integrated to achieve the goals of development (support) communication (Servaes, 2004:63; Singhal, et al., 2004:146).

Very rarely do successful public communication campaigns feature only communications through media channels (Coffman, 2002:5). Usually they coordinate media efforts with a di- 
verse mix of other communication channels, some interpersonal and some community-based, in order to extend the reach and frequency of the campaign's messages and to increase the probability that messages will successfully result in a change (Dungan-Seaver, 1999, in Coffman, 2002:5; Waisbord, 2005:81).

Similarly, disaster risk reduction public awareness activities programmes should use different types of messages, locations and delivery systems to reach their various target audiences (UNISDR, 2004:282).

A literature review (Langenhoven, 2001:67-69; Coffman, 2002:5; Snyder, 2003:171-181; Waisbord, 2005:81; UNISDR, 2004:282) reveals criteria for successful development support communication campaigns. To ensure more effective risk awareness campaigns aimed at the public, communicators within the various disaster risk reduction structures need to observe the following:

- The role of mass media: The mass media are important for the creation of awareness and knowledge, and for the stimulation of others to participate in the communication campaign process. However, successful campaigns are often those in which mass media messages are complemented by interpersonal and group communication, as well as small/alternative media channels.

- The role of interpersonal communication: Interpersonal communication, particularly through peer groups and social networks, is instrumental in attitude and behaviour changes and the maintenance of such changes.

- The message: This should be kept as simple as possible, sustained, consistent and continuously reviewed and improved. The message should be delivered at different locations in different communication environments and through the different channels that are necessary to reach various levels of stakeholders living in at-risk communities.

- Characteristics of communicator and medium: Credibility and reliability of a communicator are all extremely important and can influence the outcome of any communication campaign. The more credible, reliable and legitimate the communicator, the more effective the campaign will be.

- Characteristics of the medium: Mass media channels should be complemented by small, alternative media, such as video, film strips, posters, fliers, and audio recordings. Folk or traditional media, such as theatre, song and dance, storytelling and puppeteers involve the participation of the community in the planning and implementation of the message dissemination and hence are believable, culturally sensitive and take into cognisance local knowledge in crafting the message.

- Social context: Communication activities occur within given social contexts and cannot be abstracted out of their contexts, because it is the context which mediates the process of meaning creation by the community.

- Formative evaluation: Both communication campaign objectives and messages need to be evaluated to ensure that they fit media habits, audience predispositions and the availability of resources. Formative research can be used to segment an audience into homoge- 
neous groups, select the focus of the campaign, decide the content and tenor of the messages, choose appropriate channels, and pre-test messages and programmes.

- Communication campaign appeals: Communication campaigns must be specific, rather than general, in order to appeal to the values of audiences.

- Timeliness, comparability and accessibility: Communication campaign messages must be timely and culturally acceptable; and the channels through which they are transmitted must be accessible to the audience.

- Communication campaigns should be based on vigorous, empirically validated social science theories.

\section{Constraints to communication as an intervention for disaster risk reduction}

This article makes no assumption that communication and public awareness are the panacea for effective disaster risk reduction in South Africa. Indeed, even well- implemented campaigns could fail to bring about the desired behaviour change to enable reduced disaster risk and damage in communities.

Hornik (1989:116) observed that "the argument that information provision alone can resolve development problems makes the assumption that available resources are being efficiently utilised" - or indeed that individuals and the community have access to resources that will enable the adoption of desired practices. Hornik (1989) presented some hypotheses for the relationship/gap between acquired knowledge and resultant behaviour, each positing that change in behaviour results from an interaction between knowledge and some characteristic of an individual or community.

Given below are brief descriptions of Hornik's hypotheses:

Structural characteristics of communities: Specific aspects of community structure, such as an enabling environment and community resources for exercising individual and communal action, must be present as determinants of whether knowledge will be turned into behaviour.

Structural characteristics of individuals: For some people turning knowledge into behaviour is impossible because they lack the personal resources, such as finances or time, to undertake any recommended practices.

Community social influences: Social relationships play a major role in the diffusion of information and the adoption of new practices. In a community where the social networks are generally supportive of the goals of disaster risk reduction practitioners and their activities, knowledge garnered from a communication campaign is more readily translated into positive behaviour change than it is in areas where social networks are averse to the work and messages emanating from disaster risk reduction role players.

Learned characteristics of individuals: Experience gained through prior knowledge and beliefs about a problem, learned skills in trying to solve it, level of education, language skills, visual literacy and experience with a particular communication channel will all affect the ease with 
which individuals can handle concepts transmitted in public information campaigns, and consequently will be more likely to manifest the desired change in behaviour. People who have suffered the impacts of climate hazards in the past and those that have gained sufficient knowledge of the risks posed by climate hazards, will more readily act on information provided by disaster risk reduction communication campaigns.

\section{Concluding remarks}

Although South Africa has a marked history of climate related disasters, mechanisms of communicating and raising public awareness on the gravity of risk and the appropriate risk reduction options remain weak. This article has presented the argument that in the likely unavailability of adequate capacity within the South African government to limit risks and to mitigate climate hazard induced damage through physical infrastructure interventions - coupled with the communities' inability to make full use of economic/financial risk transfer tools - the communication of risks and risk minimising actions remains a pivotal tool for ensuring effective climate related disaster risk reduction efforts in South Africa. This is particularly so against the backdrop of a changing climate and the projections for the increased incidence of climate related hazards.

South African, regional and global disaster risk reduction frameworks all call for improved public awareness of disaster risk reduction and the cultivation of a culture of risk avoidance through communication interventions. This article has argued that the integration of fully participatory disaster risk reduction communication activities within the broader development planning framework at the various levels of government is of paramount importance.

Capacity for the execution of successful communication for development campaigns as a part of disaster risk reduction activities should be bolstered at all levels of government to enable the incorporation of at-risk communities in development planning and implementation.

This article has outlined the various established theories and strategies for the implementation of communication for development interventions. It calls for the deployment of participatory methods and strategies of Development Support Communication to ensure effective risk and risk reduction knowledge building among at-risk communities.

Central to the improvement of public awareness activities is the co-creation and management (between communities and disaster risk reduction experts and communicators) of communication strategies and methods for the building of knowledge in regard to the risks and the available, appropriate, risk reduction options for communities.

By way of a review of the completed research, this article has provided empirically validated guidance for development communicators/facilitators for the participatory planning, creation and dissemination of disaster risk reduction messages among at-risk communities. 


\section{References}

ASIAN DISASTER REDUCTION CENTRE. 2008. Total Disaster Risk Management: Good Practices 2008. A report by the Asian Disaster Reduction Centre, March 2008

BURGER, M. 1999. Participatory small-group communication as a medium for information campaigns in KwaZulu-Natal. Communicatio, 25(1 and 2): 88-94.

BURTON, S. 1998. Contemplating the future of "development communication" in South Africa today. Communicare, 1(1):88-96, June

BUYS, L. M. 2005. Status of Disaster Management in South Africa. Department of Provincial and Local Government, South Africa

COFFMAN, J. 2002. Public communication campaign evaluation: An environmental scan of challenges, criticisms, practice, and opportunities. Cambridge, MA: Harvard Family Research Project

DEPARTMENT OF ENVIRONMENTAL AFFAIRS AND TOURISM. 2006a. South African Environment Outlook. A report on the state of the environment. Executive summary and key findings. Department of Environmental Affairs and Tourism, Pretoria. 42pp.

DEPARTMENT OF ENVIRONMENTAL AFFAIRS AND TOURISM. 2006b. South African Environment Outlook. A report on the state of the environment. Department of Environmental Affairs and Tourism, Pretoria, 331pp

ENGELBRECHT, F.A. 2005. Simulations of Climate and Climate Change over Southern and Tropical Africa with the Conformal-Cubic Atmospheric Model. (In Schulze, R.E. (ed) Climate Change and Water Resources in Southern Africa: Studies on Scenarios, Impacts, Vulnerabilities and Adaptation. Water Research Commission, Pretoria, RSA, WRC Report 1430/1/05. Chapter 4, pp.57-74)

ENGELBRECHT, F.A, MCGREGOR, J.L. AND ENGELBRECHT, C.J. 2008. Dynamics of the Conformal-cubic atmospheric model projected climate-change signal over southern Africa, 2008, Int. J. Climatol. DOI:10.1002/joc. 1742

FAO. 2002. Communication for Development Manual. (A paper presented at a Bilingual Regional Workshop on Methodologies for Designing and Implementing Multimedia Communication Strategies and National Communication Policies in Niamey, Niger 1-5 April 2002)

HIRJI, R, JOHNSON, P., MARO, P. \& MATIZA CHIUTA, T. eds. 2002. Defining and Mainstreaming Environmental Sustainability in Water Resources Management in Southern Africa. Maseru/Harare/ Washington DC: SADC, IUCN, SARDC, World Bank

HORNIK, R. 1989. The Knowledge-Behaviour Gap in Public Information Campaigns: A Development Communication View. (In SALMON, C. T., 1989. Information Campaigns: Balancing Social Values and Social Change. Sage Annual reviews of Communication Research Vol 18. London: Sage)

HUESCA, R. 2003. Participatory Approaches to Communication for Development. (In Mody (ed.) International and Development Communication: A 21st Century Perspective. London: Sage Publications. pp. 209-226)

IFRC. 2005. World Disaster Report. Bloomfield CT: Kumarian Press Inc.

LANGENHOVEN, H. 2001. The Facilitating Role of the Mmabatho ICDL Centre in the Process of Women's Empowerment: A Development Communication Perspective. Potchefstroom (PUK-Thesis MA)

LITTLEJOHN, S. W. 1996. Theories of Human Communication. 5th ed. Belmont CA: Wadsworth 
MELKOTE, S. R. 1991. Communication for Development in the Third World: Theory and Practice. London: Sage

MELKOTE, S. R. \& KANDATH, K. P. 2001. Barking Up the Wrong Tree? An inward look at the discipline and practice of Development Communication. (In Melkote, S. R. and Rao, S., Critical Issues in Communication: Looking inward for answers (Essays in Honour of K. E. Eapen) New Delhi: Sage Publications. p189-204)

MELKOTE, S. R. \& STEEVES, H. L. 2001. Communication for Development in the Third World: Theory and Practice for Empowerment. 2nd Edition. New Delhi: Sage

MELKOTE, S. R. 2003. Development Communication Theories. (In Mody (ed.) International and Development Communication: A 21st Century Perspective. London: Sage Publications, pp.129-146)

MOEMEKA, A. A. 2000. Development Communication in Action: Building Understanding and Creating Participation. Maryland: University Press of America.

Msengana-Ndlela, L. 2008. Opening Remarks at the Disaster Management Indaba 2008, Gallagher Estate, Midrand (Unpublished)

SADC. 2008. Southern African Environment Outlook, Gaborone/Harare/Nairobi: SADC, SARDC, IUCN, and UNEP

SNYDER, L. B. 2003. Development Communication Campaigns. In Mody (ed.) International and Development Communication: A 21st Century Perspective. London: Sage Publications, pp.167-188)

SERVAES, J. 2004. Multiple Perspectives on Development Communication. (In OKIGBO, C.C. and ERIBO, F. 2004. Development Communication in Africa. Lanham, MD: Rowman and Littlefield. pp55-64)

SINGHAL, A, USDIN, S., SCHEEPERS, E., GOLDSTEIN, S. \& JAPHET, G. 2004. EntertainmentEducation Strategy in Development Communication. (In OKIGBO, C.C. and ERIBO, F., 2004. Development Communication in Africa. Lanham, MD: Rowman and Littlefield. pp.141-153)

SOUTH AFRICA. 2005. National Disaster Management Policy Framework, Department of Provincial and Local Government. Pretoria: Government Printer

SOUTH AFRICA. 2007. National Disaster Management Centre Inaugural Annual Report 2006/2007. Department of Provincial and Local Government. Pretoria: Government Printer

STEINBERG, F. 1996. Can Development Communication Improve Urban Management? Habitat International, 20(4):567-581

TWIGG, J. 2004. Disaster risk reduction: Mitigation and preparedness in development and emergency programming. London: Overseas Development Institute.

UNITED NATIONS INTER-AGENCY SECRETARIAT OF THE INTERNATIONAL STRATEGY FOR DISASTER REDUCTION (UNISDR). 2004. Living with Risk: Turning the tide on disasters towards sustainable development. Geneva: ISDR

UNITED NATIONS INTER-AGENCY SECRETARIAT OF THE INTERNATIONAL STRATEGY FOR DISASTER REDUCTION (UNISDR). 2005. Hyogo Framework for Action 2005-2015: Building the Resilience of Nations and Communities to Disasters. Extract from the final report of the World Conference on Disaster reduction (A/CONF.206/6)

VAN NIEKERK, D. 2005. A Comprehensive Framework for Multi-Sphere Disaster Risk reduction in South Africa. Potchefstroom (PUK-Thesis Ph. D)

VAN NIEKERK, D. 2006. Disaster Risk Management in South Africa: The function and the activity - towards an integrated approach. Politeia. 25(2):95-115 
WAISBORD, S. 2005. Five key ideas: Coincidences and challenges in development communication. (In HEMER, O. and TUFTE, T., 2005. Media and Global Change: Rethinking Communication for Development. Buenos Aires: CLACSO, pp.77- 90)

WAISBORD, S. s.a., Family Tree of Theories, Methodologies and Strategies in Development Communication. The Rockefeller Foundation. http://www.comminit.com/pdf/familytree.pdf Date of access: 29 Sept. 2008

WISNER, B., BLAIKIE, P., CANNON, T. and DAVIS, I. 2004. At Risk: Natural Hazards, People's Vulnerability and Disasters, 2nd Edition. London: Routledge

\section{Notes}

I. The author wishes to thank two anonymous reviewers for their valubale comments. 